\title{
Factors modifying the association between birth weight and blood pressure
}

\author{
Michiel F. Schreuder
}

Received: 28 June 2010 / Accepted: 5 July 2010 /Published online: 23 July 2010

(C) The Author(s) 2010. This article is published with open access at Springerlink.com

Sirs,

The Brenner hypothesis states that glomerular hyperfiltration is associated with glomerular and systemic hypertension and, in the long run, with glomerular damage with proteinuria [1]. Such hyperfiltration is seen in cases of low glomerular numbers, such as following intrauterine growth restriction (IUGR) [2].

Mühle et al. recently reported an interesting study that showed low glomerular numbers in sheep multiples, but an absence of arterial hypertension until young adulthood [3]. These authors suggest in their conclusion that this absence of arterial hypertension may be due to a multiple-hit cause of hypertension, of which they mainly mention sodium intake. I agree with their suggestion that multiple factors are responsible for final blood pressure levels, but propose that there are several additional factors that need to be considered that may be of general importance, possibly explaining some of the (absence in) differences between the experimental groups reported in Mühle et al.'s article.

First, current body weight may be used as a marker for the metabolic demand on the kidneys. The authors state that the difference between multiples and singletons was $<15 \%$, whereas they show data that the difference between singletons $(47.6 \pm 7.6 \mathrm{~kg})$ and multiples $(38.0 \pm 4.1 \mathrm{~kg}$ for twins and $38.4 \pm 1.7 \mathrm{~kg}$ for triplets) was almost $20 \%$. For twins, this body weight corresponds with the reduction in glomerular numbers $(21 \%)$, possibly indicating that, for these animals, no glomerular hyperfiltration is present and, therefore, no hypertension is expected. For the triplets, however, there is indeed an imbalance between the glomerular number reduction $(37 \%)$ and weight reduction, whereas these animals also do not show an increase in blood pressure.

\section{F. Schreuder $(\square)$}

Department of Pediatric Nephrology, 804, Radboud University

Nijmegen Medical Centre,

PO Box 9101, 6500 HB Nijmegen, The Netherlands

e-mail: m.schreuder@cukz.umcn.nl
Secondly, gender is known to modulate the effects of birth weight on blood pressure, with males being more affected. This is (in part) explained by testosterone, as gonadectomy in IUGR animals was found to prevent the rise in blood pressure [4]. Of the animals studied by Mühle et al., there were 56, 42 and $33 \%$ males in the singleton, twin and triplet group, respectively. The gender effects on blood pressure may therefore have masked the effects of birth weight.

In addition to these possible modifying factors, it is possible that the effects of IUGR based on multiple pregnancies are different from those of IUGR due to other causes (such as smoking, hypertension or dietary restraints) [5], which could explain the lack of a difference in blood pressure in sheep multiples. Whether differences in this animal model will become apparent at a later age or after additional hits remains to be studied.

Open Access This article is distributed under the terms of the Creative Commons Attribution Noncommercial License which permits any noncommercial use, distribution, and reproduction in any medium, provided the original author(s) and source are credited.

\section{References}

1. Brenner BM, Lawler EV, Mackenzie HS (1996) The hyperfiltration theory: a paradigm shift in nephrology. Kidney Int 49:1774-1777

2. Schreuder MF, Nauta J (2007) Prenatal programming of nephron number and blood pressure. Kidney Int 72:265-268

3. Muhle A, Muhle C, Amann K, Dotsch J, Nusken KD, Boltze J, Schneider H (2010) No juvenile arterial hypertension in sheep multiples despite reduced nephron numbers. Pediatr Nephrol. doi:10.1007/s00467-010-1512-3

4. Ojeda NB, Grigore D, Yanes LL, Iliescu R, Robertson EB, Zhang $\mathrm{H}$, Alexander BT (2007) Testosterone contributes to marked elevations in mean arterial pressure in adult male intrauterine growth restricted offspring. Am J Physiol Regul Integr Comp Physiol 292:R758-R763

5. Davies MJ (2005) Fetal programming: the perspective of single and twin pregnancies. Reprod Fertil Dev 17:379-386 